\title{
PROGRAMA DE EDUCAÇÃO PELO TRABALHO: RELATO DE EXPERIÊNCIA SOBRE A FORMAÇÃO DE TRABALHADORES
}

Maria de Lourdes Custódio Duarte', Anali Martegani Ferreira² ${ }^{2}$ Odete Messa Torres ${ }^{3}$, Michele Bulhosa ${ }^{4}$, Cleci Menezes Moreira ${ }^{5}$

RESUMO: O presente estudo objetiva relatar a experiência de discentes e docentes no Programa de Educação pelo Trabalho na rede de serviços de saúde de um município do Sul do Brasil no ano de 2012, enfocando ações de formação dos trabalhadores do Sistema Único de Saúde. O Programa contou com a participação de alunos dos cursos de fisioterapia e da enfermagem que desenvolveram ações no sentido de atender as necessidades dos serviços da área de Saúde Mental, Atenção Básica e do Hospital Geral. Os resultados convergem para a necessidade de formação dos profissionais da rede e ao fomento à Política de Educação Permanente em Saúde. Conclui-se sobre a importância do Programa para o ensino, serviço, gestão e comunidade, tendo em vista a percepção global dos benefícios e resultados gerados na rede de atenção no município. DESCRITORES: Promoção da saúde; Educação; Saúde; Serviços de saúde; Enfermagem.

\section{PROGRAMA DE EDUCACIÓN POR EL TRABAJO: RELATO DE EXPERIENCIA ACERCA DE LA FORMACIÓN DE TRABAJADORES}

RESUMEN: Este estudio tiene la finalidad de relatar la experiencia de discentes y docentes en el Programa de Educación por el Trabajo en la red de servicios de salud de un municipio del Sur de Brasil en el año de 2012, enfatizando acciones de formación de los trabajadores del Sistema Único de Salud. El programa ha tenido la participación de alumnos de los cursos de fisioterapia y de la enfermería que desarrollaron acciones a fin de atender a las necesidades de los servicios del área de Salud Mental, Atención Básica y del Hospital General. Los resultados apuntan para la necesidad de formación de los profesionales de la red y al fomento a la Política de Educación Permanente en Salud. Se constata sobre la importancia del Programa para la enseñanza, el servicio, la gestión y comunidad, teniendo en vista la percepción global de los beneficios y resultados generados en la red de atención en el municipio.

DESCRIPTORES: Promoción de la salud; Educación; Salud; Servicios de salud; Enfermería.

\section{WORK-BASED LEARNING PROGRAM: AN EXPERIENCE REPORT ON WORKERS' TRAINING}

ABSTRACT: The present study aims to report the experience of students and lecturers on the Work-based Learning Program in the health services network in a municipality in the South of Brazil in 2012, focussing on actions of training of the Unified Health System (SUS) workers. The program was participated in by students from the physiotherapy and nursing courses, who undertook actions so as to meet the needs of the services from the areas of Mental Health, Primary Care and General Hospital. The results converge on the need for training of the professionals of the network and for encouraging Continuous Education in Health Policy. It is concluded that the Program has importance for the teaching, service, management and community, bearing in mind the global perception of the benefits and results created in the care network in the municipality. DESCRIPTORS: Health promotion; Education; Health; Health services; Nursing.

\footnotetext{
${ }^{1}$ Enfermeira. Mestre em Enfermagem Psiquiátrica e Ciências Humanas. Doutoranda em Enfermagem. Universidade Federal do Rio Grande do Sul. Professora da Universidade Federal do Pampa. Uruguaiana-RS-Brasil

${ }^{2}$ Enfermeira. Mestre em Enfermagem. Doutoranda em Ciências da Saúde: ênfase Enfermagem. Professora da Universidade Federal do Pampa. Uruguaiana-RS-Brasil

${ }^{3}$ Enfermeira. Mestre em Saúde Coletiva. Doutoranda em Ciências da Saúde: ênfase Enfermagem.Professora da Universidade Federal do Pampa. Uruguaiana-RS-Brasil

${ }^{4}$ Enfermeira. Mestre em Enfermagem. Professora da Universidade Federal do Pampa. Uruguaiana-RS-Brasil

${ }^{5}$ Enfermeira. Doutora em Fisiologia Cardiovascular. Professora da Universidade Federal do Pampa. Uruguaiana-RS-Brasil
} 


\section{INTRODUÇÃO}

A pluralidade dos contextos vivenciados pelas diferentes regiões brasileiras exige políticas públicas capazes de atender adequadamente às necessidades advindas desta diversidade ${ }^{(1)}$. Assim, Programas de Educação pelo Trabalho (PET) tornam-se instrumentos de valorização dos profissionais de saúde para atenção à formação dos estudantes dos cursos de graduação, de acordo com as necessidades do Sistema Único de Saúde (SUS) ${ }^{(2)}$.

Neste contexto, o Ministério da Saúde do Brasil lançou uma série de editais de PET Saúde como parte integrante do Programa Nacional de Reorientação da Formação Profissional em Saúde (Pró-Saúde) que objetiva a articulação entre as instituições de ensino superior e o servidor público de saúde. Logo, esse Programa potencializa respostas às necessidades concretas da população brasileira, mediante a formação de recursos humanos, a produção do conhecimento e a prestação dos serviços com vistas ao fortalecimento do SUS ${ }^{(3)}$.

Desta maneira, esta iniciativa visa aproximação entre formação de graduação e as necessidades da população, diminuindo o distanciamento entre os mundos acadêmico e o da prestação dos serviços de saúde, que vem sendo apontado como um dos responsáveis pela crise do setor nesta área ${ }^{(3)}$. Além disso, o Pró-Saúde objetiva a consolidação da rede de serviços articulados com as demandas sociais dos usuários, visando a integralidade da assistência ${ }^{(4)}$.

Inserido neste cenário, o município de Uruguaiana - Rio Grande do Sul foi contemplado em março de 2012 com o PET Redes de Atenção, decorrente da parceria entre a Secretaria Municipal de Saúde com a Universidade Federal do Pampa (UNIPAMPA). Esse Programa iniciou suas atividades no município como uma estratégia do Pró-Saúde, para que as ações de educação e saúde sejam consolidadas no âmbito da rede de serviços, com vistas a reorientar a formação em saúde.

Portanto, esse artigo relata a experiência de discentes e docentes no PET na rede de serviços de saúde do município de Uruguaiana no ano de 2012, enfocando ações educativas trabalhadores do SUS de três campos de atuação: Saúde Mental, Atenção Básica e Hospital Geral. Assim, pretende-se contribuir na divulgação das ações do PET Redes à comunidade acadêmica, a fim de estimular a parceria entre as secretarias de saúde e as instituições de ensino superior na execução de projetos e programas, com vistas à formação de discentes e profissionais do setor da saúde.

\section{ORGANIZAÇÃODO PROCESSO DE TRABALHO DO PET REDES DE ATENÇÃO}

O PET Redes de Atenção pressupõe a necessidade de interação entre Ensino e a Rede de Serviços. No município de Uruguaiana sua organização contou com a presença de um tutor, seis preceptores (profissionais dos serviços de saúde) e 12 bolsistas e voluntários selecionados dos cursos de enfermagem, fisioterapia e farmácia para a realização das atividades. Essas ações visaram a qualificação em serviço dos profissionais do SUS e iniciação ao trabalho de discentes dos cursos de graduação da área da saúde.

Dessa maneira, para o início das atividades do Programa os discentes foram divididos em quartetos nos três campi de atuação - identificados pelo município como estratégicos na formação de profissionais: Saúde Mental, Atenção Básica e o Hospital Geral. Foi realizada uma reunião com os preceptores alocados em cada serviço, para que os mesmos pudessem discorrer sobre as necessidades dos setores e assim poder dar início ao planejamento das atividades com os acadêmicos.

Para a orientação das atividades, além da ajuda dos preceptores, o PET Redes contou com auxílio de três docentes distribuídos nas três áreas. Logo, foi necessário realizar reuniões setoriais de forma quinzenal, a partir do mês de maio de 2012, com os pequenos grupos de discentes, docentes e preceptores.

Essas reuniões ocorreram nos serviços de saúde da rede e tinham o propósito de planejar o assunto das capacitações a serem desenvolvidas, a metodologia utilizada e o público alvo. Dessa maneira, as capacitações iniciaram-se no mês de agosto de 2012, a fim de possibilitar o planejamento e indicação de profissionais pelos gestores dos serviços.

As ações em educação permanente, com base nas reflexões desenvolvidas a partir da integração entre acadêmicos, profissionais e docentes, contribuíram na formação dos trabalhadores dos serviços de saúde da rede nos diferentes contextos do município de Uruguaiana.

\section{RESULTADOS}

O serviço de saúde mental foi escolhido para sediar o PET Redes de Atenção com o intuito de ajudar na reorientação dos profissionais para um atendimento voltado para os pressupostos da Reforma Psiquiátrica ${ }^{(5)}$. Para isso, foram escolhidos o Ambulatório de Saúde Mental, o Centro de Atenção Psicossocial (CAPS) II e o CAPS Álcool e Drogas (AD) para receber a equipe do programa. 
O tema central dirigido aos profissionais desses três serviços foi sobre o matriciamento em saúde mental ${ }^{(6-7)}$, indo ao encontro das últimas normativas do Ministério da Saúde. Para tanto, a coordenação desses três serviços indicaram 10 profissionais para participarem da qualificação que ocorreu em quatro dias, com a frequência semanal no mês de agosto/2012, totalizando 20 horas. O material utilizado pelos bolsistas foi orientado por uma docente e na metodologia utilizaram-se textos, slides e filmes. Assim, ao final da capacitação os profissionais verbalizaram a importância dessa ação para o trabalho que desenvolvem no seu cotidiano, avaliando a atividade como propulsora de novos saberes.

A Atenção Básica caracteriza-se por um conjunto de ações de saúde, no âmbito individual e coletivo, que abrangem a promoção e a proteção da saúde, a prevenção de agravos, o diagnóstico, o tratamento, a reabilitação e a manutenção da saúde ${ }^{(1)}$. Nesse contexto, a Unidade Básica de Saúde (UBS) número 14 foi escolhida pelo gestor de saúde do município como um serviço estratégico na reorientação da atenção básica da região.

O coordenador dessa UBS identificou como necessidade a formação dos profissionais na perspectiva das novas diretrizes do Suporte Básico de Vida (SBV) e primeiro atendimento de crianças vítimas de injúrias não intencionais, intoxicações, quedas, fraturas, aspiração de corpo estranho e queimaduras. Assim, no mês de setembro, totalizando 22 horas, foram desenvolvidas quatro oficinas no próprio serviço com seis profissionais sobre esses assuntos, enfocando a demonstração prática do SBV tanto para adultos quanto para crianças.

No âmbito social não se tem percebidas campanhas de prevenção de forma estruturada tendo em vista o aumento dos índices de acidentes por queimaduras. Essas campanhas colocariam, em debate, os acidentes envolvendo fogo e as situações consideradas previsíveis, oferecendo alerta à sociedade como um todo, além de estimular a formação de profissionais para esses $\operatorname{casos}^{(8)}$.

Por fim, o hospital geral Santa Casa foi escolhido tendo em vista sua importância para o contexto da Atenção em Saúde do referido município. Como forma de superar o modelo vigente (hegemônico) de atenção em saúde, pautado fortemente no saber médico $^{(4)}$, o gestor dessa instituição, em parceria com os profissionais, identificou a necessidade de trabalhar o assunto Humanização ${ }^{(6)}$ no atendimento. Foram, então, promovidos quatro encontros com 12 trabalhadores no mês de setembro de 2012, na qual foi utilizada, como norteador das discussões, a cartilha sobre a Política Nacional de Humanização do Ministério da Saúde. Essa formação teve carga horária total de 20 horas.

O processo de humanização nas instituições de saúde surgiu, na atualidade, para que se possa repensar as práticas cotidianas de trabalho, reformulando o atendimento prestado aos usuários desses serviços ${ }^{(9)}$. Dessa maneira, evidenciou-se desconhecimento por parte de alguns trabalhadores sobre o assunto, o que trouxe à tona a necessidade de debates no próprio local de trabalho.

Após o término das capacitações, nas três áreas do setor saúde, foram entregues os certificados a todos os trabalhadores participantes; documento reconhecido como de extrema importância pelos profissionais, principalmente em uma região de escassos cursos de aperfeiçoamento profissional.

Destaca-se que ações de qualificação desenvolvidas nos serviços contemplados pelo PET tiveram como foco a implementação da Educação Permanente (EP), na qual os processos de educação dos trabalhadores da saúde se fazem a partir da problematização do processo de trabalho. Dessa forma, sugere-se que as necessidades de formação e desenvolvimento dos trabalhadores sejam pautadas pelas demandas de saúde das pessoas e das populações, e tenham como objetivos a transformação das práticas profissionais e da própria organização do trabalho ${ }^{(10)}$.

\section{CONSIDERAÇÕES FINAIS}

A educação pelo trabalho em programas como o apresentado neste relato tem contribuído para o fortalecimento da integração docente-assistencial, aproximando a universidade das mais diversas instituições de saúde das regiões contempladas. Suas ações vêm permitindo a qualificação de trabalhadores dos serviços de saúde, favorecendo o aprimoramento na formação dos estudantes de diversos cursos envolvidos neste projeto. Portanto, enfatiza-se sua importância para o ensino, serviço, gestão e comunidade tendo em vista a percepção global dos benefícios e resultados gerados na rede de atenção nos municípios contemplados.

\section{REFERÊNCIAS}

1. Ministério da Saúde (BR), Conselho Nacional das Secretarias Municipais de Saúde. O SUS de A a Z: garantindo saúde nos municípios [Internet]. $3^{\mathrm{a}}$ ed. Brasília; 2009 [acesso em 08 set 2012]. (Série F:

Cogitare Enferm. 2014 Jan/Mar; 19(1):166-9 
comunicação e educação em saúde). Disponível: http:// portal.saude.gov.br/portal/arquivos/pdf/sus_3edicao_ completo.pdf.

2. Ministério da Saúde (BR), Ministério da Educação (BR). Portaria Interministerial $n^{\circ} 422$, de 3 de março de 2010: estabelece orientações e diretrizes técnicoadministrativas para a execução do Programa de Educação pelo Trabalho para a Saúde - PET Saúde, instituído no âmbito do Ministério da Saúde e do Ministério da Educação [Internet]. Brasília; 2010 [acesso em 07 set 2012]. Disponível: http://portal.saude. gov.br/portal/arquivos/pdf/portaria_422_2010.pdf.

3. Ministério da Saúde (BR), Ministério da Educação (BR). Portaria Conjunta $n^{\circ} 6$, de 17 de setembro de 2010: institui no âmbito do Programa de Educação pelo Trabalho para a Saúde (PETSaúde), o PET-Saúde/ Saúde Mental [Internet]. Brasília; 2010 [acesso em 15 fev 2012]. Disponível: http://www.brasilsus.com.br/ legislacoes/conjuntas/105684-6.html.

4. Bonfada D, Cavalcante JRLP, Araújo DP, Guimarães J. A integralidade da atenção à saúde como eixo da organização tecnológica nos serviços. Ciênc. saúde colet. [Internet] 2012;17(2) [acesso em 02 set 2012]. Disponível: http://dx.doi.org/10.1590/S141381232012000200028

5. Delfini PSS, Reis AOA. Articulação entre serviços públicos de saúde nos cuidados voltados à saúde mental infantojuvenil. Cad. Saúde Pública. [Internet] 2012;28(2) [acesso em 02 set 2012]. Disponível: http:// dx.doi.org/10.1590/S0102-311X2012000200014

6. Ministério da Saúde (BR). Política Nacional de Humanização: HumanizaSUS [Internet]. Brasília (DF); 2005 [acesso em 21 fev 2010]. Disponível: http:// portal.saude.gov.br/portal/saude/cidadao/area.cfm?id_ area $=1342$.

7. Ministério da Saúde (BR). Relatório final da Oficina de Trabalho para "Discussão do Plano Nacional de Inclusão das Ações de Saúde Mental na Atenção Básica”. Brasília; 2001.

8. Duarte MLC, Lemos L, Zanini LNN, Wagnes ZI. Percepções da equipe de enfermagem sobre seu trabalho em uma unidade de queimados. Rev. Gaúcha Enferm. [Internet] 2012;33(1) [acesso em 10 set 2012]. Disponível: http://dx.doi.org/10.1590/S1983-14472012000100011

9. Duarte MLC, Noro A. Humanização: uma leitura a partir da compreensão dos profissionais da enfermagem. Rev. Gaúcha Enferm. [Internet] 2010;31(4) [acesso em
15 set 2012]. Disponível: http:// dx.doi.org/10.1590/ S1983-14472010000400011.

10. Duarte MLC, Oliveira AI. Compreensão dos coordenadores de serviços de saúde sobre educação permanente. Cogitare enferm. [Internet] 2012;17(3) [acesso em 16 set2012]. Disponível: http://ojs.c3sl.ufpr.br/ ojs2/index.php/cogitare/article/viewFile/29292/19042. 